\title{
The educational component of senior house officer posts: differences in the perceptions of consultants and junior doctors
}

\author{
M. Baker and P.D. Sprackling ${ }^{1}$ \\ Clinical Research Fellow, Office of the Postgraduate Dean and ${ }^{1}$ Regional Adviser in General Practice, \\ University of Nottingham, Medical School, Queen's Medical Centre, Nottingham, NG7 2UH, UK
}

Summary: The aims of this study were to elicit general practitioner (GP) trainee's perceptions of the educational structure of their hospital posts, to compare them with those of consultants who had GP trainees as senior house officers (SHOs) in their departments and to examine the use of educational objectives in the hospital component of vocational training for general practice. A confidential postal questionnaire was sent to all the GP trainees (165 doctors) in the hospital component of their vocational training schemes (VTS) for general practice in Trent Region and all the consultants (161 doctors) in Trent who had GP trainees in their SHO posts on that date.

Responses were received from 136 trainees $(82 \%)$ and 134 consultants $(83 \%)$. Educational objectives were stated as existing in the SHO post by 31 trainees (23\%) and by 62 consultants (46\%). Of those doctors who said that objectives existed, 19 of the trainees (61\%) and 40 of the consultants (65\%) said that the objectives were useful. Only nine (29\%) of the trainees who stated that educational objectives existed felt that they were being put into practice by senior staff, compared with $41(66 \%)$ of consultants who had made that statement. Of all respondents, 113 trainees $(87 \%)$ and 100 consultants $(77 \%)$ agreed or strongly agreed that the use of educational objectives would be beneficial to the trainees.

Only $10(7 \%)$ of trainees said that they received no teaching in their current posts. Forty trainees $(32 \%)$ and 88 consultants (67\%) said that teaching took place in protected time. Both groups cited consultants as the member of staff giving the most teaching. Ninety-six consultants $(73 \%)$ replied that it was possible for GP trainees to obtain study leave, but 102 trainees (75\%) either had experienced difficulties in obtaining study leave or had not attempted to obtain study leave. Trainees and consultants differed appreciably in their perceptions of the amount of assessment and feedback which was provided for GP trainees.

The use of educational objectives in the hospital component of vocational training was felt to be beneficial by both consultants and GP trainees. Consultants were more likely than trainees to report the use of educational objectives, protected teaching time, GP-orientated teaching, ability of trainees to attend VTS half-day release and the provision of assessment and feedback to trainees.

\section{Introduction}

Since the advent of vocational training for general practice there have been many studies describing educational activities in the general practitioner (GP) training year. ${ }^{1-5}$ There has been comparatively little interest in the educational content of the 2 years GP trainees spend as senior house officer (SHO) in the hospital component of vocational training schemes (VTS). Those studies which have been conducted have shown that trainees are dissatisfied with the posts in general and with the educational provision in particular. ${ }^{6-8}$ There have

Correspondence: M. Baker, M.B., Ch.B., M.R.C.G.P. Accepted: 6 October 1993 been no studies exploring the views of consultants on the hospital posts used for vocational training, although one study has sought their views on the training of SHOs in medicine. ${ }^{9}$

The first aim of this project was to elicit GP trainees' perceptions of the educational structure of their hospital posts and to compare these with those of consultants who had GP trainees as SHOs in their departments. The second aim was to examine the use of educational objectives in the hospital component of vocational training. Even though educational objectives have been widely used by the teaching profession because they provide direction for the educational process and provide a basis for assessment, ${ }^{10}$ they have been 
largely ignored in the context of medical education for SHOs. The use of such objectives has been called for ${ }^{11,12}$ and they have been implemented in some schemes. ${ }^{13}$ Several Royal Colleges have produced a core curriculum for SHOs ${ }^{14}$ or objectives for GP trainees in their hospital posts. ${ }^{15,16}$ Most recently the Royal College of General Practitioners with other Royal Colleges and specialist organizations have produced a series of joint statements on the content of vocational training for general practice which contain sets of objectives and curricula for different specialities. ${ }^{17-23}$ Despite this surge of interest, no studies yet have looked at the use of educational objectives in SHO posts or vocational training for general practice.

The study was conducted before new arrangements for paying salaries of junior doctors were instituted in April 1993. ${ }^{24}$ Under these arrangements, funds were transferred from National Health Service (NHS) provider Units or Trusts to postgraduate deans so that the deans now hold funds to provide $50 \%$ of the basic salaries for all doctors in approved training posts. The rationale behind this policy was to separate funding for training and service, implying that a substantial part of junior doctors' time should be spent in training. This study looks at education in hospital posts used for vocational training in the period immediately before the new funding arrangements were instituted.

\section{Method}

One hundred and sixty-five GP trainees in the hospital component of formal vocational training schemes were identified by contacting the postgraduate secretaries for the 12 VTS in the region. The secretaries were asked to provide the names of all trainees on the VTS who would be in hospital posts on 1 October 1992. They were also asked to identify those consultants who had GP trainees in their SHO posts on that date and 161 such consultants were identified. Replies were received from every VTS.

Semi-structured interviews were conducted with 10 trainees and four consultants in the region to ask about the educational content of the SHO post. The information gathered was used as the basis for the construction of two questionnaires, one aimed at trainees and one aimed at consultants. The trainee questionnaire looked at the educational content of the SHO post held by the trainee on 1 October 1992: in particular at the use of educational objectives, the type and quality of teaching and the availability of assessment and feedback. Consultant questionnaires also addressed these issues. The questionnaires were then sent to the 165 trainees and 161 consultants identified by the VTS secretaries. The trainees and consultants were assured that their replies would be confidential. A reminder was sent to non-responders after 4 weeks.

Comparisons were made between the replies of trainees and those of consultants using chi-square. The data were analysed on computer using the SPSSX statistical package.

\section{Results}

Questionnaires were sent to 165 GP trainees and 161 consultants of whom $136(82 \%)$ and $134(83 \%)$ responded, respectively.

Trainees and consultants were asked if educational objectives existed for the posts held by the trainees. The term 'educational objectives' was defined as a written list of the knowledge and skills which the trainee was expected to acquire in the post. Where objectives did exist, respondents were asked if they felt that they were useful and realistic. The responses are set out in Table I. All respondents were asked to indicate the extent to which they agreed that the use of educational objectives would be beneficial to the trainees in their posts. A

Table I The use of educational objectives in the SHO posts held by GP trainees. Figures are numbers (percentages) of trainees and consultants who replied to each question

\begin{tabular}{lccc}
\hline & $\begin{array}{c}\text { Trainees } \\
(\mathrm{n}=136)\end{array}$ & $\begin{array}{c}\text { Consultants } \\
(\mathrm{n}=134)\end{array}$ & $\mathrm{P} \dagger$ \\
\hline $\begin{array}{l}\text { Educational objectives } \\
\text { exist for this post }\end{array}$ & $31(23)$ & $62(46)$ & $<0.001$ \\
$\begin{array}{l}\text { Objectives found to be } \\
\text { realistic* }\end{array}$ & $21(70)$ & $42(68)$ & $\mathrm{NS}$ \\
$\begin{array}{l}\text { Objectives found to be } \\
\text { useful* }\end{array}$ & $19(61)$ & $40(65)$ & $\mathrm{NS}$ \\
$\begin{array}{l}\text { Objectives are put into } \\
\text { practice by senior staff* }\end{array}$ & $9(29)$ & $41(66)$ & $<0.001$ \\
\hline
\end{tabular}

*Where educational objectives were said to be in existence; $\uparrow$ chi-squared test. NS $=$ not significant. 
total of 113 trainees $(87 \%)$ compared with 100 consultants $(77 \%)$ agreed or strongly agreed with this (chi-square $=4.389$, d.f. $=1, P<0.05$ ).

Trainees were asked whether they received any teaching in their current post and only $10(7 \%)$ received no teaching. 'Protected time' for teaching was defined as time free from service commitments, and trainees and consultants were asked if any teaching occurred in such protected time. The results are set out in Table II. Both trainees and consultants were asked who gave most teaching to the trainees in their posts. Both groups cited consultants as the member of staff giving the most teaching. There was, however, a significant difference (chi-square $=12.659$, d.f. $=1, P<0.001$ ) with 49 trainees $(42 \%)$ saying consultants gave most teaching against 72 consultants $(66 \%)$ who felt that they gave most teaching. There was also a significant difference between trainees and consultants when asked if they considered the teaching given to GP trainees to be GP orientated. Eightyseven trainees $(64 \%)$ responded that teaching was very GP orientated or sometimes GP orientated, compared to 116 consultants $(87 \%)$ who felt that their teaching was GP orientated (chi-square = 16.629 , d.f. $=1, P<0.001$ ). Furthermore, when those trainees who had educational objectives were compared with those who had not, the former were significantly more likely to feel that their teaching was GP orientated (chi-square $=9.706$, d.f. $=1$, $P<0.01$ ).

The question of whether study leave was available was put to trainees and consultants. Twentyeight trainees $(21 \%)$ had experienced difficulties in obtaining study leave and $74(54 \%)$ had not attempted to obtain study leave, although six of these respondents qualified their response by stating that they had been told that study leave would not be available. The remaining $34(25 \%)$ who replied to this question stated that they had no difficulties in obtaining study leave. Of the 134 consultants who replied to this question, only 12 $(9 \%)$ said that it was not possible for GP trainees to obtain study leave. Opportunities for attendance at

Table II Response to the question 'Does any teaching occur in protected time?' Figures are numbers (percentages) of trainees and consultants who responded to the question

\begin{tabular}{lcc}
\hline & $\begin{array}{c}\text { Trainees } \\
(\mathrm{n}=128)\end{array}$ & $\begin{array}{c}\text { Consultants } \\
(\mathrm{n}=130)\end{array}$ \\
\hline Yes & $25(20)$ & $59(45)$ \\
No & $88(69)$ & $43(33)$ \\
Sometimes & $15(12)$ & $28(22)$ \\
\hline
\end{tabular}

Chi-square $=33.137, P<0.001$.
VTS half-day release were also examined, and the perceptions of trainees and consultants regarding this may be seen in Table III.

Trainees and consultants were also asked whether any assessment of the trainee's performance was conducted and whether there was any feedback from consultants to trainees. The responses to these questions can be seen in Table IV.

\section{Discussion}

The high response rates achieved from both trainees and consultants were very encouraging, and show a substantial degree of interest in this field from both groups of doctors. It was not possible to match individual trainees with individual consultants as trainees often work for more than one consultant within a 6 month attachment. However, the response rates of $82 \%$ and $83 \%$ mean that for most of these posts, replies must have been received from trainees and consultants in the same department. The results therefore give a good indication of what these two groups of doctors think about the educational content of the hospital posts used for vocational training in Trent Region.

A major finding of this study has been the differences in the perceptions of GP trainees and consultants regarding the educational content of the SHO posts used in vocational training. Consultants were more likely than trainees to report the use of educational objectives, protected teaching time, GP-orientated teaching, ability of trainees to attend VTS half-day release, and the provision of assessment and feedback to trainees. These differences may arise in part from the different perspectives of these two groups, but it seems likely that there is a substantial communication failure which had detrimental effects on the education of this group of junior doctors.

The one question which elicited broad consensus between trainees and consultants was whether the use of educational objectives would be beneficial to the GP trainees in their hospital posts. A large

Table III Responses to the question 'Is it possible for GP trainees to attend the VTS half-day release?' Figures are numbers (percentages) of trainees and consultants who answered the question

\begin{tabular}{lcc}
\hline & $\begin{array}{c}\text { Trainees } \\
(\mathrm{n}=136)\end{array}$ & $\begin{array}{c}\text { Consultants } \\
(\mathrm{n}=133)\end{array}$ \\
\hline Always & $41(30)$ & $74(56)$ \\
Sometimes & $84(62)$ & $58(44)$ \\
Never & $11(8)$ & $1(1)$ \\
\hline
\end{tabular}

Chi-square $=18.798$, d.f $=2, P<0.001$. 
Table IV Responses to the questions concerning provision of assessment and feedback. Figures are numbers (percentages) of all trainees and consultants

\begin{tabular}{|c|c|c|c|}
\hline & $\begin{array}{l}\text { Trainees } \\
(\mathrm{n}=136)\end{array}$ & $\begin{array}{l}\text { Consultants } \\
(\mathrm{n}=134)\end{array}$ & $\mathrm{P} \dagger$ \\
\hline $\begin{array}{l}\text { There is an introductory } \\
\text { session at the start of the post }\end{array}$ & $43(32)$ & $89(66)$ & $<0.001$ \\
\hline $\begin{array}{l}\text { There is assessment part of the } \\
\text { way through the post }\end{array}$ & $36(27)$ & $79(59)$ & $<0.001$ \\
\hline $\begin{array}{l}\text { There is assessment at } \\
\text { the end of the post }\end{array}$ & $28(21)$ & $80(60)$ & $<0.001$ \\
\hline There is no assessment & $30(22)$ & $12(9)$ & $<0.01$ \\
\hline $\begin{array}{l}\text { I do not know whether I } \\
\text { am being assessed }\end{array}$ & $71(52)$ & Not applicable & \\
\hline $\begin{array}{l}\text { There is a written record } \\
\text { of the assessment }\end{array}$ & $19(14)$ & $41(31)$ & $<0.01$ \\
\hline There is no feedback* & $44(32)$ & $22(16)$ & $<0.01$ \\
\hline $\begin{array}{l}\text { I do not know whether I will } \\
\text { receive any feedback* }\end{array}$ & $61(45)$ & Not applicable & \\
\hline
\end{tabular}

*Feedback defined as ranging from a written report to some comments in passing; †chi-squared test.

majority of all respondents to both questionnaires agreed that these were, or would be, of benefit to the trainees. There was also agreement between trainees and consultants that where objectives existed, they were useful and realistic. There was disagreement, however, on whether objectives were put into practice by senior staff, with relatively few trainees perceiving this to be the case. It is striking that trainees found educational objectives to be useful just by their existence and even without implementation by senior staff. Perhaps if consultants knew the degree to which the use of these objectives was valued by the trainees then they might be more appreciative of objectives as an educational tool.

One possible reason why consultants and juniors might have such differing perspectives on the educational component of the posts might be that the juniors are not aware when they are being helped to learn by practical experience rather than didactic teaching. It could be argued that if the juniors were aware of the educational objectives of the post they would be more likely to recognize the learning opportunities when they arose and be more likely to appreciate when senior staff took advantage of these to teach. In addition, if consultants had more training in educational method, they might then make better use of learning opportunities which would then implement the objectives.

This study found marked differences in the perceptions trainees and consultants had regarding assessment and feedback. Similar differences in the perception of provision of feedback were noted in a previous study of consultants and SHOs. ${ }^{25}$ In order for assessment to be of educational value to junior doctors, the results of the assessments must be passed on to them. It is striking that in this study most of the trainees did not know whether they were being assessed. Simple improvements in communication between consultants and trainees could have a dramatic effect in improving the provision of assessment and feedback to trainees. It has been said that many consultants think that they provide feedback to their juniors over a cup of coffee, but the juniors think a cup of coffee is a cup of coffee! VTS course organizers and hospital clinical tutors could play an important role in ensuring that consultants give trainees written reports and carry out assessments at appropriate intervals. Most consultants who responded to this study reported that they were already performing assessments on trainees, so the creation of a more structured process should not carry substantial workload implications.

It is encouraging that this study has demonstrated that both trainees and consultants have a high degree of interest in the educational content of the SHO post. However, it would seem that valuable educational opportunities are being lost due to lack of communication. If departments draw up educational objectives and design assessment procedures without informing trainees, then their value is limited and the time and energy will have been wasted.

It would be desirable if all SHO trainee posts had the following features in common. There should be an introductory session at the start of the post where the educational structure of the post is defined, the trainees should be given a set of 
objectives for the post, methods of assessment and feedback should be explained to the trainee and the trainees should be told that they will receive a written report on all assessments. Consultants and VTS course organizers should meet to decide the educational content of each post and suggest educational objectives. These could subsequently be adapted to each trainee. The differing needs of departments and firms could be considered, and modifications to the process made where necessary. This system would then give opportunities for dialogue between consultants and trainees which would be of educational benefit in itself. Since on formal schemes, trainees rotate through posts every 6 months, all the doctors involved would rapidly become accustomed to the process. They would

\section{References}

1. Kelly, D.R. Twenty years of vocational training in the west of Scotland: the practice component. Br J Gen Pract 1991, 41: 492-495.

2. Difford, F. \& Hughes, R.C.W. Experience of using rating scales for the assessment of vocational trainees in general practice. Br J Gen Pract 1991, 41: 360-364.

3. Oxford Region Course Organisers and Regional Advisers Group. Priority Objectives for General Practice Vocational Training, 2nd edn. Royal College of General Practitioners, London, 1988 (Occasional Paper 30).

4. Cyna, A.M. \& Przyslo, F.R. Are the recommendations being met in the general practice year of vocational training? Trainees' views in the West Midlands Region. Br Med J 1987, 294: 416-418.

5. Carne, S. (ed.) What others do: is vocational training for general practice working? Modern Med 1986, June, 59-60.

6. Kearley, K. An evaluation of the hospital component of general practice vocational training. Br J Gen Pract 1990, 40: 409-414.

7. Crawley, H.S. \& Levin, J.B. Training for general practice: a national survey. $\mathrm{Br}$ Med $J$ 1990, 300: 911-915.

8. Reeve, H. \& Bowman, A. Hospital training for general practice: views of trainees in the North Western region. $\mathrm{Br}$ Med J 1989, 298: 1432-1434.

9. Grant, J., Marsden, P.\& King, R.C. Senior house officers and their training. $B r$ Med J 1989, 299: 1263-1268.

10. Grondland, N.E. \& Linn, R.L. Measurement and Evaluation in Teaching, 6th edn. MacMillan, New York, 1990.

11. Tait, I. Agreed educational objectives for the hospital period of vocational training. J Assoc Course Organisers 1987, 2: 179-182.

12. Bligh, J.G. \& Harden, R.M. Briding the gap between hospital experience and general practice during vocational training. Med Teacher 1990, 12: 169-173.

13. Evans, S. Hospital component of vocational training. J Assoc Course Organisers 1987, 3: 46.

14. Royal College of Physicians: Education Committee. Education and Training for Senior House Officers. Royal College of Physicians, London, 1992. have a better understanding of the educational content of each post and perhaps this could help eliminate the marked discrepancies of perceptions between trainees and consultants.

\section{Acknowledgements}

We wish to thank all the consultants and GP trainees in Trent Region who participated in this study for their co-operation; the three postgraduate deans in the region for their support and assistance and Ms Lindsay Groom of the Department of General Practice in the University of Nottingham for her advice on the study and on preparation of this paper.

15. Royal College of General Practitioners (RCGP), Royal College of Obstetricians and Gynaecologists. Recommendations for Arrangements for General Practitioner Vocational Training in Obstetrics and Gynaecology. RCGP, London, 1992.

16. Royal College of General Practitioners (RCGP), Royal College of Psychiatrists. Joint Statement on General Practitioner Vocational Training in Psychiatry. RCGP, London, 1992.

17. Royal College of General Practitioners (RCGP). The Quality of Hospital-based Education for General Practice. RCGP, London, 1993.

18. Royal College of General Practitioners (RCGP), Royal College of Obstetricians and Gynaecologists. General Practitioner Vocational Training in Obstetrics and Gynaecology. RCGP, London, 1993.

19. Royal College of General Practitioners (RCGP), British Paediatric Assocation. The Paediatric Component of Vocational Training for General Practice. RCGP, London, 1993.

20. Royal College of General Practitioners (RCGP), British Association for Accident and Emergency Medicine. General Practitioner Vocational Training in Accident and Emergency Medicine. RCGP, London, 1993.

21. Royal College of General Practitioners (RCGP), British Geriatrics Society. General Practitioner Vocational Training in Geriatric Medicine. RCGP, London, 1993.

22. Royal College of General Practitioners (RCGP), Association for Palliative Medicine. Palliative Medicine Content of Vocational Training for General Practice. RCGP, London, 1993.

23. Royal College of General Practitioners (RCGP), Royal College of Psychiatrists. General Practitioner Vocational Training in Psychiatry. RCGP, London, 1993.

24. Department of Health: National Health Service Management Executive. Funding of Hospital Medical and Dental Training Grade Posts. NHSME EL(92)63.

25. Grant, J. \& Marsden, P. Training Senior House Officers by Service Based Learning. Joint Centre for Education in Medicine, London, 1992. 